Please quote as: Blohm, I.; Bretschneider, U.; Leimeister, J. M. \& Krcmar, H. (2010): Does collaboration among participants lead to better ideas in IT-based idea competitions - An empirical investigation. In: Hawai'i International Conference on System Sciences (HICSS) 2010, Kauai, USA. 


\section{Does Collaboration among Participants Lead to Better Ideas in IT-based Idea Competitions? An Empirical Investigation}

\author{
Ivo Blohm \\ Technische Universität München \\ Chair for Information Systems (I17) \\ ivo.blohm@in.tum.de \\ Jan Marco Leimeister \\ Universität Kassel \\ Chair for Information Systems \\ leimeister@uni-kassel.de
}

\author{
Ulrich Bretschneider \\ Technische Universität München \\ Chair for Information Systems (I17) \\ ulrich.bretschneider@in.tum.de \\ Helmut Krcmar \\ Technische Universität München \\ Chair for Information Systems (I17) \\ krcmar@in.tum.de
}

\begin{abstract}
Research has shown that idea competitions are a promising approach for integrating customers into open innovation activities. Furthermore research on open innovation shows that most innovations are the result of intensive collaboration processes in which many individuals contribute according to their specific strengths [20, 22, 39, 47]. So, fostering collaboration among idea contributors in idea competitions might be a very fruitful approach for unleashing the customers' entire creative potential for "open $R \& D$ " and thus making idea competitions even more successful.

This paper reports on a field study in which idea contributors could collaborate during idea generation and idea elaboration in an IT-based idea competition using the wiki technology. In order to test whether this kind of user collaboration positively influences the quality of the ideas submitted we conducted an empirical in-depth analysis of idea quality in an idea competition. Our results show that user collaboration enhances idea quality and that inducing user collaboration is a viable design element for making idea competitions more effective. This can contribute to a more successful design, implementation and operation of idea competitions as well as to better outcomes. The article concludes with a discussion of customer groups collaborating in idea competitions (more extrinsically and more intrinsically motivated customers) and shows possibilities for future research in this area.
\end{abstract}

\section{Introduction}

In the 20th century, many leading industrial companies generated, developed and commercialized ideas for innovations in self-reliance. Nowadays, companies are increasingly rethinking the fundamental ways of managing their innovation activities. Opening up company boundaries in order to utilize external resources for innovation activities becomes more and more important. For this emerging competitive strategy of Open Innovation customers are frequently seen as enormous potential for generating innovations $[15,28,51]$.

In literature and practice, idea competitions are discussed, and generally acknowledged as an effective practice for integrating customers into the early stages of the innovation process [26]. Although idea competitions sound like a familiar method to get access to customer knowledge there is only limited research that studied this customer integration practice in detail $[16,50]$. Most available literature solely focuses on studying idea competitions from the perspective of social science, especially business administration. For instance, Walcher [54] explored characteristics and motivations of participants of idea competitions. Lacking are studies that address the design of internet-based platforms for idea competitions which typically address the domain of information science. First research in this field has been conducted by Leimeister et al. [30], who studied technical and organizational design elements of an idea competition in order to influence the customers' participation. But so far no research has been carried out on design elements for maximizing the outcome of idea competitions that can be defined as quantity and the quality of the ideas submitted.

Generally, one way for enhancing idea quality can be seen in offering the "right" incentives to the participants [50]. Another measure for enhancing idea quality could be fostering collaboration among idea contributors. Research shows that most 
innovations are in general not the result of a single inventor but rather of collaboration processes where many individuals contribute and combine their individual knowledge, experiences, and strengths [20, $22,39,47]$. Processes of intensive user collaboration can often be found in virtual communities where anecdotal evidence shows that some users have bred high quality products in decentralized collaboration settings [53]. These products can often compete with products developed in traditional innovation processes. Examples comprise, e.g. the Wikipedia project or open source software [23, 29]. In such communities initially developed ideas are picked up by other community members and are elaborated step by step. Each participant can not only contribute own ideas but also connect with idea contributors that submitted similar or complementary ideas, and elaborate ideas in collaboration. Thus, the various networks/teams collaboratively elaborate ideas that might be better, more meaningful, and more relevant than those initially submitted. Bretschneider et al. [9] assume that ideas generated in this manner are often enriched with solution information for customer needs. Solution information represents not only the customer's needs and wishes but also customer based suggestions that describe how to transfer these ideas into marketable products [52].

Focusing on this aspect, this paper aims to explore collaboration as design element in idea competitions. We investigate whether user collaboration in idea competitions influences idea quality positively. Therefore we conducted a field test in which a collaboration tool based on the wiki technology was implemented on an idea competition's online platform and we compare the idea quality of ideas elaborated collaboratively and ideas contributed without any collaboration.

The paper is organized as follows: In Section 2 we present a literature review for describing the state of the art of idea competitions as well as the complex construct of idea quality. Section 3 describes the realworld case of SAPiens as research context. Section 4 presents the design of the field test, the used collaboration instruments as well as the assessment of idea quality. In section 5 our empirical findings on measuring idea quality in idea competitions and the effects of collaboration are presented. In section 6 these results are discussed and recommendations for the design of idea competitions are deducted. Finally, section 7 gives an outlook for possible future research areas.

\section{Theoretical Background}

\subsection{Idea Competitions}

An idea competition can be defined as an invitation of an organizer, namely a firm, to the general public or a targeted group to submit contributions to a certain topic within a timeline. An idea reviewers committee evaluates these contributions and selects the winner [13, 54].

In conducting idea competitions firms aim to integrate customers in the process of gaining and generating new innovation ideas in the early phases of new product development. By opening up the innovation activities to customers more potential perspectives and ideas for creating innovation can be gained. Easy put, the amount of innovation potential that is poured into the innovation funnel is increased and hence the likelihood of developing disruptive innovation rises. Thus, utilizing the "collective intelligence" or "wisdom of crowds" of its own customer base is the underlying principle of idea competitions [31, 49]. In order to leverage this potential an inherent competition character is forced by awarding the best ideas: the participants' motivation, creativity and efforts are encouraged leading to submission of better quality [41].

As research on idea competitions in the context of customer integration in innovation processes is limited, idea competitions can be described as a phenomenon of practice. Today, they are an elaborated method for active customer integration $[13,14]$. There are some prominent examples underpinning the enormous potential of this approach. In 2006 IBM invited its customers and employees to the "Innovation Jam" idea competition. In the end, more than 140.000 participants contributed more than 46.000 ideas. The best ideas resulted in various projects as software applications and services for micro-finance institutions. Adidas [41], Motorola, Henkel or Fujitsu Siemens are only few further examples.

Leimeister et. al. [30] as well as Ebner et al. [13] developed a broad framework for categorizing idea competitions and revealed major trends in and best practices for running idea competitions. In general, tasks are kept generic, offering a large solution space to potential participants for targeting as many customers as possible. Submissions include a brief description of the idea, regularly limited to a maximum length of five DIN A4 pages. Incentives for the customers' participation often comprise cash prices of more than 1.000 EUR. The typical duration varies between 4 and 26 weeks. In practice, idea 
competitions are generally run via Internet-based platforms based on the toolkit approach. After submission the ideas are presented on the platform and can be regarded, discussed or even evaluated by other participants. For companies, internet technology facilitates the realization of an idea competition, as the Internet provides access for a larger group of customers and facilitates submission of ideas for participants. To sum-up, Internet applications lower the efforts and costs for participants as well as for organizers [41].

\subsection{Evaluating idea quality}

Since all innovation begins with creative ideas [27], the evaluation of new ideas is heavily related to the assessment of their inherent creativity. But creativity and idea quality are both complex constructs. And due to their "fuzziness" a broad range of different evaluation methods for assessing idea quality in idea competitions is applied in practice. In general, the evaluation process is carried out by an independent expert jury. But the methods in use range from unstructured discussions to complex rating schemes based on consensual assessments of the referees.

Furthermore, many different rating criteria are applied in idea competitions for assessing idea quality, so that no real best practices can be deducted. However, assessing idea quality has been a subject to creativity, group support system and innovation researchers for years and various metrics for assessing the quality of creative products and ideas have been discussed in the course of time. An extensive literature review revealed that most of these measures can be categorized into one of the four different dimensions novelty, relevance, feasibility or elaboration (cp. Table 1)

Table 1. Dimensions of idea quality

\begin{tabular}{ll}
\hline Novelty & {$[1,3,5,7,8,10,12,17,21,24,25$,} \\
& $27,32-34,45,54,56]$ \\
\hline Relevance & {$[2,3,5,7,8,10,17,25,27,32,34$,} \\
& $40,45,56]$ \\
\hline Feasibility & {$[2,3,5,7,8,10,12,17,19,24,25$,} \\
& $27,32,34,40,45,48,54,56]$ \\
\hline Elaboration & {$[1,7,8,10,12,17,21,27,33,34$,} \\
& $40,54,56]$ \\
\hline
\end{tabular}

Today there is still no universal definition of creativity [56], but there is consensus about that creative solutions are generally characterized by being new and useful $[1,37,40,42]$. Novelty is often defined as being unique or rare. In this context new

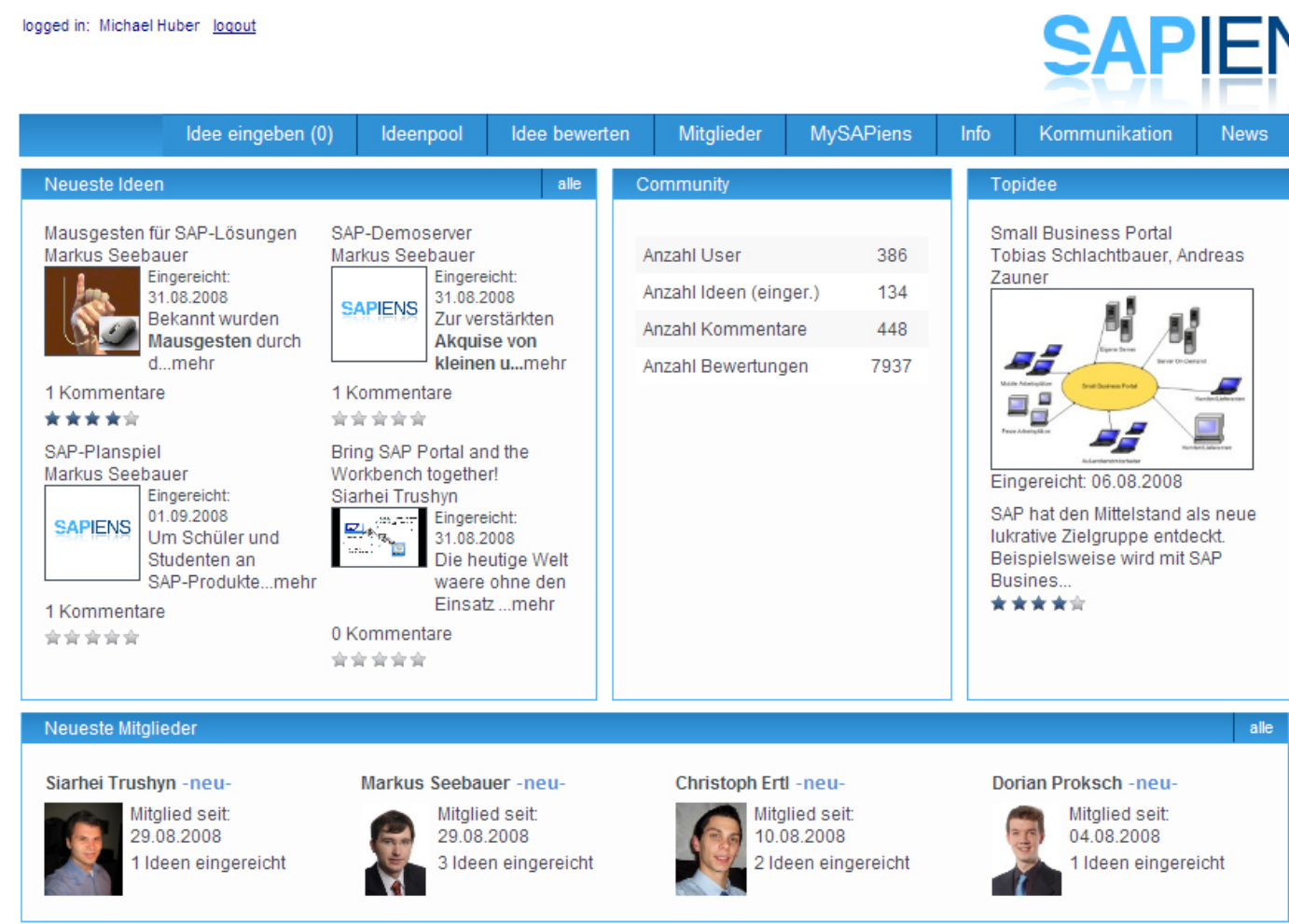

Figure 1. Homepage of the SAPiens Idea Competition 
ideas have not been expressed before [34]. A closely related trait of novelty is originality. Original ideas are not only new but also surprising, imaginative, uncommon or unexpected [3, 12] and many researchers see originality as the most important facet of creativity $[8,46,54]$. Another attribute of novelty is their paradigm relatedness $[7,17,38]$. This refers to an idea's transformational character and describes the degree to which an idea helps to overcome established structures and is radical or revolutionary $[7,11]$. From a new product development perspective, an idea's paradigm relatedness refers to its innovativeness.

However, an idea's novelty is not sufficient for being unique and useful. Usefulness is the extent to which the idea responds to or solves a problem that is tangible and vital [1, 12]. This dimension is also named as an idea's value or relevance [12, 27, 34]. In the scope of new product development this refers frequently to an idea's financial potential $[10,19,32$, $45,48]$, the strategic importance in terms of enabling competitive advantages $[10,32,45]$ as well as the customer benefit an idea endows [41, 54].

From the innovator's perspective an idea's feasibility is another vital dimension of idea quality. This dimension captures the ease with which an idea can be transformed into a commercial product [27, 48] and the fit between the idea and the organizer $[10,32,45]$. In this context this fit is two-pronged. From an internal perspective fit refers to the organizer's strategy, capabilities and resources. From an external perspective, this refers to the fit between the idea and the organizer's image.

Another trait of a high quality idea is its elaboration which can be seen as the extent of being complete, detailed and well understandable [12]. Furthermore, this refers not only to an idea's description but also to its maturity [19].

\section{Research context: the SAPiens idea competition}

SAPiens was an internet based idea competition initiated by the ERP software producer SAP. The idea competition was run in summer 2008 over a period of 14 weeks and targeted users of SAP software. The invited SAP users were asked to submit ideas that improve the SAP software or that bring out radical innovations in the scope of the SAP software.

Ideas had to be submitted via an internet toolkit that was designed and implemented especially for the SAPiens idea competition and could be visited only after registration. Each submitted idea, phrased in a maximum length of a DIN A4 page, was visualized in an idea pool, a separate section of the online platform that was visible for all visitors of the internet platform. In this idea pool all ideas could be examined, evaluated and picked up for further elaboration by the participants. Figure 1 shows the homepage of the SAPiens online platform.

During the competition 127 users registered on the SAPiens website. Of those users, 39 actively participated in the competition by submitting at least one idea. The contributors submitted 57 ideas in total. The rest of the 127 registered users participated by voting and commenting other user's submissions or simply lurked. The average participant was male and young: $72 \%$ of participants were male and $78 \%$ of the particants were between 20 and 25 years old.

The idea competition consisted of two phases. In the first phase ideas could be submitted on the online platform and picked up for collaboration. In the second phase the ideas were evaluated by an independent expert jury. The 10 best ideas were rewarded by monetary and non-monetary prizes 6.000 EUR in total.

\section{Methodology}

\subsection{Research Design}

For analyzing the influence of collaboration on idea quality the submitted ideas were categorized into two distinct groups. The first group $(n=36)$ contained solely ideas which were collaboratively submitted by a group of participants. The second group $(n=21)$ contained ideas that were submitted only by one participant, respectively. Group assignment did not take place randomly. Based on collaboration activities there has been a self selection of participants. In this quasi-experiment idea quality served as independent variable and user collaboration as dependent variable.

\subsection{Collaboration instruments}

Collaboration among the participants was made possible by using the wiki technology. Wikis are not only a well-established and easy-to-use technology but also fostering collaboration of many users and promoting the creation of social networks among the formerly anonymous users. Every single user was able to pick up every other's ideas in the idea pool in order to make edits. Each idea description contained an "edit this page" button opening a wiki page for making amendments (cp. figure 2). 


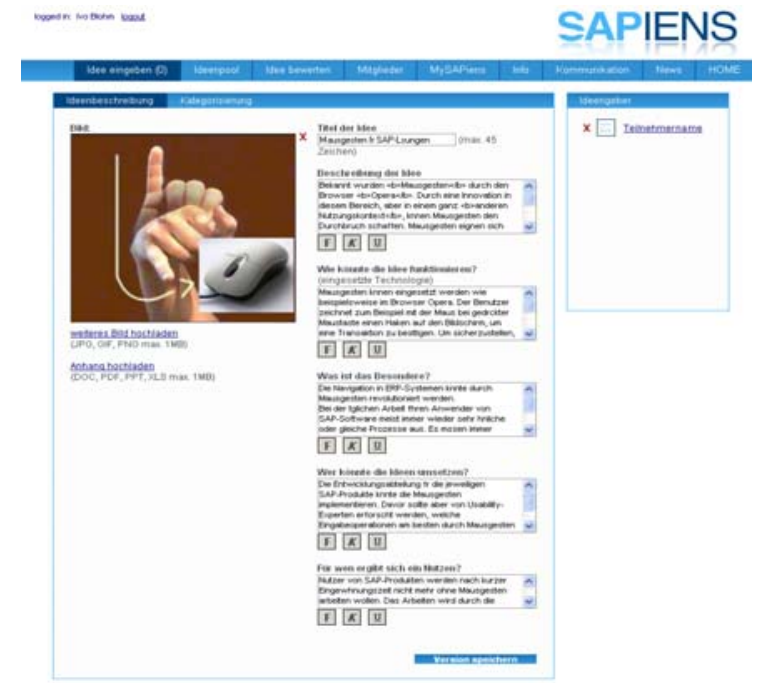

Figure 2. Editing ideas via the wiki technology

Moreover different communication tools and community functionalities were implemented for fostering collaboration. Every participant's contact details, e.g. including email address, skype nickname and phone number, were visible within the user profiles, which were accessible for all participants. In addition each idea description could be commented on, enabling extensive discussions on the online platform.

\subsection{Assessing idea quality}

Based on the literature review in section 2.2 a suitable evaluation scale consisting of 15 items was developed (cp. appendix). Each of idea quality's distinct dimensions was operationalized by three different items (novelty consists of two dimensions). Subsequently, we evaluated the ideas using Amabile's Consensual Assessment Technique (CAT) [1] which has been severally used for evaluating customer generated new product ideas $[19,27,36$, $41,54]$. Using this method ideas are evaluated by a jury consisting of experts in the given domain. In our case the jury consisted of 7 referees, which were either university professors, employees of the initiator SAP or the German SAP University Competence Centers. For evaluation the idea descriptions were copied into separate evaluation forms which contained the scales for idea evaluation as well. The evaluation forms were handed out to the referees in a randomized order. All judges were assigned to rate the ideas with the 15 different items on a rating scale from 1 (lowest) to 7 (highest). Each member of the jury evaluated the ideas independent from the others. The referees did not know which ideas were edited collaboratively by the participants. In order to assess idea quality validly and reliably we factor analyzed the evaluation items.

The results of this evaluation process were also used for identifying the winners of the SAPiens ideas competition.

\section{Empirical Findings}

\subsection{Idea quality in idea competitions}

Initially we performed an exploratory factor analysis with SPSS 17.0. Already the first iteration mirrored the supposed item structure exactly and with novelty, feasibility, relevance and elaboration four clearly interpretable factors could be identified. Further, it was checked whether the data was appropriate for explanatory factor analysis by calculating the Measures of Sampling Adequacy (MSA) for the whole data structure as well as the individual items. As all MSA values were above 0.6, exploratory factor analysis was applicable and no items had to be eliminated [35]. However the items N6, R1, C3 and F3 showed high factor loadings on other factors, too. Due to this ambiguity these items were excluded. The reliability of the factors was checked using Cronbach's Alpha. Alpha should be higher than 0.7 for indicating an acceptable value for internal consistency [35]. With Alphas of at least 0.841 this criteria was met.

Subsequently, we tested these factors using confirmatory factor analysis using Amos 17.0. The factors novelty, relevance and concretization showed very high Composite Reliabilities and high values for the Average Variance Explained (AVE) so that convergent validity can be assumed (cp. tables 2 and 3 ). Values of 0.6 regarding the Composite Reliability and 0.5 for the AVE can be seen as minimum values for indicating a good measurement quality [4]. The factor feasibility did not meet the minimum requirements for convergent validity so that we had to eliminate this factor from further analysis.

The discriminant validity of the remaining factors was checked by using the Fornell-Larcker criteria which claims that one factor's AVE should be higher than its squared correlation with every other factor [18]. Table 3 depicts that discriminant validity can be assumed for the three factors mentioned above. 
Table 3. Discriminant validity of the factors

\begin{tabular}{lccc}
\hline & Novelty & $\begin{array}{c}\text { Rele- } \\
\text { vance }\end{array}$ & $\begin{array}{c}\text { Elabo- } \\
\text { ration }\end{array}$ \\
\hline & AVE & Squared Multiple Correlations \\
\hline Novelty & 0.83 & & \\
\hline Relevance & 0.90 & 0.04 & \\
\hline Elaboration & 0.83 & 0.08 & 0.02 \\
\hline
\end{tabular}

All Individual Item Reliabilities exceed the minimum threshold of 0.5 [4]. Hence, the good reliability based on Cronbach Alpha is confirmed.

Finally, we checked the global fit of our model by conduction a Chi-Square $\left(\chi^{2}\right)$-test (cp. Table 4$)$. The $\chi^{2}$-test was significant: the measure between $\chi^{2}$ values and degrees of freedom (df)-ratio was 2,425, well below the upper threshold of 5.00, which indicates an adequate fit [55]. Thus, the instrument was successfully validated using both exploratory and confirmatory factor analysis.

Furthermore, we checked the inter-rater reliability of the judgments by calculating Intra-ClassCorrelation (ICC) Coefficients as recommended by [1]. According to Amabile ICC Coefficients have to be higher than 0.5 for indicating a sufficient degree of inter-rater reliability. In our case most ICC Coefficients were $>0.7$ or slightly below. Interestingly, only the items that were excluded in the course of the explanatory and the confirmatory factor analysis failed to meet this required minimum interrater reliability significantly. Thus, the CAT can be seen as very appropriate method for evaluating idea quality in idea competitions.

We constructed a quality index reaching from 0 to 100 and that was checked for normal distribution by conducting a Kolmogorov-Smirnov-Test. The result was not significant with $p=0.785$. So, normality of the data can be assumed (cp. figure 3 ).

The three validated factors explain about $82 \%$ of the original variance. The first factor novelty explained about $51 \%$. So, high quality ideas captivate first and foremost through being new. The second important factor was the ideas' relevance accounting for $22 \%$. Elaboration shows only a minor explanatory content for idea quality. It explains only about $10 \%$ of the items' variance. The forth factor feasibility was eliminated during the confirmatory factor analysis. But this factor would have stated only for $7 \%$. Thus, this elimination was insignificant for measuring the submitted ideas' quality.

Overally, the initiator was very satisfied with the submissions quality. Of the 57 submitted ideas 7 were completely new to the initiator and considered as "high quality ideas". This ties in with current research about customer integration in which about $10-20 \%$ of customer generated new product ideas are labeled as new and valuable $[6,27,54]$. The other ideas were either described as minor improvements of current products or were already known. Ideas reached quality scores between 3 and 56. The winning idea described an innovative strategy for acquiring new customers, which did not use SAP solutions as they preferred to rely on free-of-charge

Table 2. Factor analysis of idea quality

\begin{tabular}{|c|c|c|c|c|c|c|c|}
\hline \multirow[b]{2}{*}{ Item } & \multicolumn{4}{|c|}{ Factor } & \multirow{2}{*}{$\begin{array}{c}\text { Cron- } \\
\text { bach's } \alpha\end{array}$} & \multirow{2}{*}{$\begin{array}{c}\text { Individual } \\
\text { Item } \\
\text { Reliability }\end{array}$} & \multirow[b]{2}{*}{$\begin{array}{l}\text { Composite } \\
\text { Reliability }\end{array}$} \\
\hline & $\begin{array}{c}\text { Novelty } \\
\text { (1) }\end{array}$ & $\begin{array}{c}\text { Rele- } \\
\text { vance (2) }\end{array}$ & $\begin{array}{c}\text { Elabo- } \\
\text { ration (3) }\end{array}$ & $\begin{array}{c}\text { Feasi- } \\
\text { bility (4) }\end{array}$ & & & \\
\hline N3 & 0.965 & 0.167 & 0.106 & -0.049 & \multirow{5}{*}{0.956} & 0.938 & \multirow{5}{*}{0.96} \\
\hline N4 & 0.890 & 0.255 & 0.160 & -0.101 & & 0.879 & \\
\hline N1 & 0.853 & 0.257 & 0.237 & -0.087 & & 0.853 & \\
\hline N2 & 0.839 & 0.220 & 0.207 & -0.065 & & 0.825 & \\
\hline N5 & 0.706 & 0.210 & 0.157 & -0.283 & & 0.604 & \\
\hline R3 & 0.281 & 0.909 & 0.102 & -0.084 & \multirow{2}{*}{0.841} & 0.794 & \multirow{2}{*}{0.95} \\
\hline $\mathrm{R} 2$ & 0.359 & 0.846 & 0.099 & -0.150 & & 0.879 & \\
\hline $\mathrm{C} 2$ & 0.276 & 0.023 & 0.851 & 0.198 & \multirow{2}{*}{0.887} & 0.762 & \multirow{2}{*}{0.91} \\
\hline $\mathrm{C} 1$ & 0.212 & 0.180 & 0.847 & 0.217 & & 0.896 & \\
\hline F1 & -0.235 & -0.194 & 0.140 & 0.912 & \multirow{2}{*}{0.769} & - & \multirow[b]{2}{*}{-} \\
\hline $\mathrm{F} 2$ & -0.064 & -0.028 & 0.230 & 0.760 & & - & \\
\hline Eigenvalues & 5.58 & 2.37 & 1.12 & 0.77 & & & \\
\hline Variance Explained & $50.78 \%$ & $21.57 \%$ & $10.17 \%$ & $7.03 \%$ & & & \\
\hline
\end{tabular}

KMO criterion $=0.773$; Bartlett-test of specificity: $\chi 2=605.88 p=0.000$; principal component analysis; varimax-rotation; $n=57$.

The bold values indicate the attribution of the variables to one of the three factors. 
open source software.

\subsection{Effect of collaboration on idea quality}

In the first instance, the arithmetic mean of the idea's quality in both groups (collaboration / no collaboration) was calculated. A comparison shows that there is practically no difference between the two groups. Whilst the group 1 (collaboration) contains ideas with an average quality score of 34.5 the second group's (no collaboration) average quality is 35.2. Based on this data, no positive influence of collaboration can be found.

However, this finding could be the determined methodologically. According to Reinig/Briggs/Nunamaker [44] the quality of an ideation session is not completely reflected by averaging the ideas' quality scores. The quality of an ideation session should rather be calculated by counting the ideas exceeding a previously defined minimum quality as bad or already known ideas are worthless for the initiator. The advantage of this approach can easily be described with a small example: If one compares two groups, it could be possible, that the first group contains more good ideas than the second. But contemporaneously, there could be much more low quality ideas in the first group so that the second group contains ideas of a higher average quality.

Based on this good idea count idea quality was compared in the two groups again. 5 of the 7 good ideas have been edited collaboratively.

In order to test whether a positive impact of collaboration could be determined based on this finding the ideas have been grouped again. Group 1 contained the best 5 collaboratively compiled ideas. Every collaboratively compiled idea was submitted by at least 2 idea contributors at the SAPiens Internet platform. Group 2 comprised the best 5 ideas submitted by a single participant. This group rearrangement led to an amplification of the mean differences between the two groups. Group 1 (collaboration) had an average quality score of 53.58 and group 2 (no collaboration) one of 47.65. A twotailed t-Test showed that this difference is significant with $p=0.017$. Thus, a positive impact of collaboration of participants on idea quality could be determined.

\section{Discussion}

The original purpose of this empirical study was to explore the effect of user collaboration on idea quality in idea competitions. In this context an indepth analysis of idea quality was performed. The present investigation is the first study that provides sound empirical data on idea quality and user collaboration in idea competitions.

From our field test several central lessons can be learned. Firstly, our research has shown that idea competitions are effective means for gaining new and valuable ideas for generating innovations. Secondly, our research shows that user collaboration in idea competitions is a viable design element for positively influencing idea quality. Our data indicates that collaboration enhances the quality of the submissions, albeit this effect has to be approved in a bigger sample.

Artefacts of usage on the online platform as well as the results of extensive observations give a clear impression of the motivation for collaboration in the SAPiens idea competition, of the personal benefit for the users, and of the role incentives play. Generally, it can be assumed that there are different types of participants in idea competitions that can be activated by different measures. On the one hand there are people that are highly intrinsically motivated and do

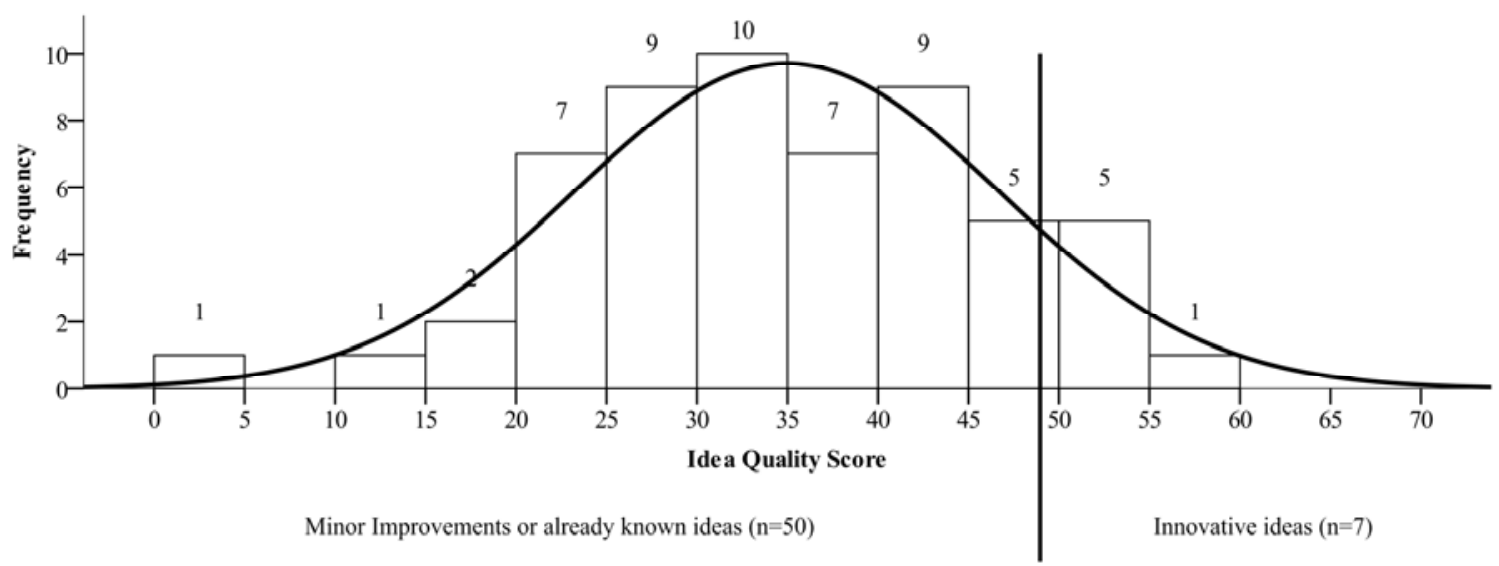

Figure 3. Distribution of idea quality scores 
not need direct compensation as incentive for participation. These idea contributors are activated due to social motives like identification with the initiator and the participants' community, altruism, further developing one's skills as well as the motives of intellectual stimulation and fun [30, 54]. On the other hand there are more extrinsically motivated idea contributors that participate for the sake of the competition's prizes, the career options offered at the organizer for the winner, etc. Our field test showed that implanting collaboration tools in idea competitions is a first step towards activating both customer groups with different measures. The customer group striving for direct compensation can be motivated for participating by offering attractive incentives. The more intrinsically motivated group can be motivated by building a virtual community for innovations around the idea competition as these participants can be activated through means fostering and guiding social interaction. Thus, implanting collaboration instruments like the wiki technology is a viable measure for activating these customers.

But in this context it has to be beared in mind that the majority of participants are motivated by a mixture of intrinsic and extrinsic motives. Thus, collaboration and competition might be partly exclusive design elements. Collaboration seems less likely to occur in very competitive situations in which many participants compete for few, very attractive prizes. In such situations many potential collaborators won't collaborate as the activation of the extrinsic motive of direct compensation overweighs the intrinsic ones. This situation can frequently be found in sport events. For instance, Franke and Shah [20] revealed that the extent of collaboration among members in sporting communities decreases with the extent of inherent competition. Thus, a misleading incentive structure will hamper intensive collaboration among participants.

\section{Conclusion}

The SAPiens idea competition has turned out to be an effective way for integrating customers into innovation processes. This study explored the relationship of collaboration among idea contributors in idea competitions and idea quality in detail.

For the purpose of new product development gaining as many high quality ideas as possible is the main objective of idea competitions. Our findings can benefit the design of organisational and technical structures of idea competitions in order to reach that goal as these open innovation systems consist not only of IT-based platforms but also demands adequate organisational values, norms, and rules [43]. So, initiators of idea competitions should implement collaboration functionalities on the platform and foster collaboration through suitable incentives for making participants collaborate. For example, organizers could incentivise collaboration directly. Another incentive structure in idea competitions could be handing out prizes rather to teams than to single participants. Doing so, teams would collaborate internally and compete externally - and the benefits of the both design elements collaboration and competition could be combined.

Our findings show limitations regarding the small sample size. Future work should develop theoretical foundations to give underpinning to these findings. Researchers should also aim at giving further empirical support to these findings in other samples as well as to the motives of collaborating idea contributors. Furthermore, more mechanisms to support and harvest the wisdom of crowds are a prosperous area for future research. For instance, the expert evaluation in the scope of this field test accounted for about 60 hours in total and revealed an enormous potential for collaborative filtering. Developing valid rating mechanisms for usergenerated content, other users, and organizers are promising starting points for supporting incentives and activation in open innovation activities in general, and in idea competitions in particular. Moreover, there is a conceptual gap between the generation and selection of ideas and their transformation into innovations. We need to explore further methods, concepts and tools to support the processing of ideas to innovations, also using the wisdom of crowds or collective intelligence.

Acknowledgement: This paper resulted from the research project GENIE (Gemeinschaftsgestützte Innovationsentwicklung für Softwareunternehmen; FKZ: 01FM07027). GENIE is funded by the German Federal Ministry of Education and Research. It is a joint project of the Technische Universität München and various partners. For further information, see www.projekt-genie.de.

\section{References}

[1] T.M. Amabile, Creativity in context. Update to social psychology of creativity, Westview Press, Oxford, 1996.

[2] T.M. Amabile, R. Conti, H. Coon, J. Lazenby, and M. Herron, Assessing the work environment for creativity, Academy of Management Journal, 39, 5, 1996, pp. 11541184. 
[3] S.H. Ang, and S.Y.M. Low, Exploring the dimensions of ad creativity, Psychology \& Marketing, 17, 10, 2000, pp. 835-854.

[4] R.P. Bagozzi, and Y. Yi, On the evaluation of Structural Equatation Models, Journal of the Academy of Marketing Sciences, 16, 1, 1988, pp. 74-94.

[5] H. Barki, and A. Pinsonneault, Small group brainstorming and idea quality: Is electronic brainstorming the most effective approach?, Small Group Research, 32, 2, 2001, pp. 158-205.

[6] M. Bartl, H. Ernst, and J. Füller, Community Based Innovation - eine Methode zur Einbindung von Online Communities in den Innovationsprozess, In: Herstatt, C., and Sander, J.G., (eds.), Produktentwicklung mit virtuellen Communities. Kundenwünsche erfahren und Innovationen realisieren., Gabler, Wiesbaden, 2004, pp. 141-167.

[7] S.P. Besemer, and K. O'Quin, Analyzing creative products: Refinement and test of judging tool, Creativity Research Journal, 20, 2, 1986, pp. 115-126.

[8] S.P. Besemer, and K. O'Quin, Confirming the threefactor creative product analysis matrix model in an american sample, Creativity Research Journal, 12, 4, 1999, pp. 287-296.

[9] U. Bretschneider, J.M. Huber, J.M. Leimeister, and H. Krcmar, Community for Innovations: Developing an Integrated Concept for Open Innovation, Proceeding of the International Federation for Information Processing (IFIP8.6), Madrid, 2008.

[10] S.H. Cady, and J. Valentine, Team Innovation and perceptions of consideration. What difference does diversity make?, Small Group Research, 30, 6, 1999, pp. 730-750.

[11] H.H.C.M. Christiaans, Creativity as design criterion, Creativity Research Journal, 14, 1, 2002, pp. 41-54.

[12] D.L. Dean, J.M. Hender, T.L. Rodgers, and E.L. Santanen, Identifying quality, novel, and creative Ideas: Constructs and scales for idea evaluation, Journal of the Association for Information Systems, 7, 10, 2006, pp. 646698.

[13] W. Ebner, J.M. Leimeister, and H. Krcmar, Community Engineering for Innovations: The Ideas Competition as a method to nurture a Virtual Community for Innovations, R \& D Management, 40, in press, 2010.

[14] W. Ebner, M. Leimeister, U. Bretschneider, and H. Krcmar, Leveraging the wisdom of crowds: Designing an IT-supported ideas competition for an ERP software company, Proceeding of the 41st Annual Hawaii International Conference on System Sciences (HICCS 41), Big Island, Hawaii, 7.-10.01., 2008.

[15] E. Enkel, J. Perez-Freije, and O. Gassmann, Minimizing Market Risks Through Customer Integration in New Product Development: Learning from Bad Practice, Creativity and Innovation Management, 14, 4, 2005, pp. 425-437.

[16] H. Ernst, Virtual customer integration: Maximizing the impact of customer integration on new product performance, In: Albers, S., (ed.), Cross-functional innovation management: Perspectives from different disciplines, Gabler, Wiesbaden, 2004, pp. 191-208.
[17] R.A. Finke, T.B. Ward, and S.M. Smith, Creative cognition. Theory, research and applications, MIT Press, Cambrigde, 1996.

[18] C. Fornell, and D.F. Larcker, Evaluating Structural Equation Models with Unobservable Variables and Measurement Error, Journal of Marketing Research, Vol. 18, (1981), S. 39-50., 18, 2, 1981, pp. 39-50.

[19] N. Franke, and C. Hienerth, Prädikatoren der Qualität von Geschäftsideen: Eine empirische Analyse eines OnlineIdeen-Forums, Zeitschrift für Betriebswirtschaft Special Issue, 6, 4, 2006, pp. 47-68.

[20] N. Franke, and S. Shah, How communities support innovative activities: an exploration of assistance and sharing among end-users, Research Policy, 32, 1, 2003, pp. 157-178.

[21] N. Franke, E. von Hippel, and M. Schreier, Finding commercially attractive user innovations: A test of leaduser theory, Journal of Product Innovation Management, 23, 4, 2006, pp. 301-315.

[22] M. Gascó-Hernández, and T. Torres-Coronas, Virtual teams and their search for creativity, In: Godar, S.H., and Pixy Ferris, S., (eds.), Virtual and collaborative teams, PA: Idea Group, Hershey, 2004, pp.

[23] J. Giles, Internet encyclopaedias go head to head Nature, 438, 2005, pp. 900-901.

[24] D. Horn, and G. Salvendy, Product creativity: conceptual model, measurement and characteristics, Theoretical Issues in Ergonomics Science, 7, 4, 2006, pp. 395-412.

[25] S. Im, and J.P. Workman Jr, Market orientation, creativity, and new product performance in hightechnology firms, Journal of Marketing, 68, 2, 2004, pp. 114-132.

[26] X. Koufterous, M. Vonderembse, and J. Jayaram, Internal and External Integration for Product Development: The Contingency Effects of Uncertainty, Equivocality, and Platform Strategy, Decision Sciences, 36, 1, 2005, pp. 97133.

[27] P. Kristensson, A. Gustafsson, and T. Archer, Harnessing the creative potential among users, The Journal of Product Innovation Management, 21, 1, 2004, pp. 4-14.

[28] P. Kristensson, P.R. Magnusson, and J. Matthing, Users as a hidden resource for creativity: findings from an experimental study on user involvement, Creativity \& Innovation Management, 11, 1, 2002, pp. 55-61.

[29] K.R. Lakhani, and E. von Hippel, How open source software works: "free" user-to-user assistance, Research Policy, 32, 7, 2003, pp. 923-943.

[30] J.M. Leimeister, M. Huber, U. Bretschneider, and H. Krcmar, Leveraging Crowdsourcing - ActivationSupporting Components for IT-based Idea Competitions, Journal of Management Information Systems, 26, 1, in press, 2009.

[31] B. Libert, and J. Spector, We are smarter than me. How to unleash the power of crowds in your business, Wharton School Publications, Upper Saddle River, 2008.

[32] G.L. Lilien, P.D. Morrison, K. Searls, M. Sonnack, and E. von Hippel, Performance assessment of the lead user 
idea-generation process for new product development, Management Science, 48, 8, 2002, pp. 1042-1059.

[33] C. Lüthje, Kundenorientierung im Innovationsprozess. Eine Untersuchung der Kunden-Hersteller-Interaktion in Konsumgütermärkten, Deutscher Universitäts-Verlag, Wiesbaden, 2000.

[34] K.R. MacCrimmon, and C. Wagner, Stimulating ideas through creative software, Management Science, 40, 11, 1994, pp. 1514-1532.

[35] N.K. Malhotra, Marketing Research. An applied orientation, Pearson, Upper Saddle River, 2007.

[36] J. Matthing, P. Kristensson, A. Gustafsson, and A. Parasuraman, Developping succesful technology-based services: the issue of identifying and involving innovative users, Journal of Services Marketing, 20, 5, 2006, pp. 288297.

[37] R.E. Mayer, Fifty years of creativity research, In: Sternberg, R.J., (ed.), Handbook of Creativity, Cambrige University Press, Cambrige, 1999, pp. 449-460.

[38] M. Nagasundaram, and R.P. Bostrom, The structuring of creative processes using GSS: A framework for research, Journal of Management Information Systems, 11, 3, 1994, pp. 87-114.

[39] J.E. Nemiro, Connection in creative virtual teams, Journal of Behavioral and Applied Management, 2, 2, 2001, pp. 92-112.

[40] W. Niu, and R.J. Sternberg, Cultural influences on artistic creativity and its evaluation, International Journal of Psychology, 36, 1, 2001, pp. 225-241.

[41] F.T. Piller, and D. Walcher, Toolkits for idea competitions: a novel method to integrate users in new product development, R\&D Management, 36, 3, 2006, pp. 307-318.

[42] J.A. Plucker, R.A. Beghetto, and G.T. Dow, Why isn't creativity more important to educational psychologists? Potentials, pitfalls, and future directions in creativity research, Educational Psychologist, 39, 2, 2004, pp. 83-96.

[43] C.K. Prahalad, and V. Ramaswamy, The future of competition: Co-creating unique value with customers, Havard Business School Press, Boston, MA, 2004.

[44] B.A. Reinig, R.O. Briggs, and J.F. Nunamaker Jr, On the measurement of ideation quality, Journal of Management Information Systems, 23, 4, 2007, pp. 143161.

[45] L. Rochford, Generating and screening new product ideas, Industrial Marketing Management, 20, 4, 1991, pp. 287-296.

[46] M.A. Runco, and S.O. Sakomoto, Experimental studies of creativity, In: Sternberg, R.J., (ed.), Handbook of Creativity, Cambridge University Press, Cambridge, 1999, pp. 62-92.

[47] M. Sawhney, G. Verona, and E. Prandelli, Collaborating to Create: The Internet as a Platform for Customer Engagement in Product Innovation, Journal of Interactive Marketing, 19, 4, 2005, pp. 4.

[48] J.H. Soll, Ideengenerierung mit Konsumenten im Internet, Deutscher Universitäts-Verlag, Wiesbaden, 2006.
[49] J. Surowiecki, The wisdom of crowds, Anchor Books, New York, 2005.

[50] O. Toubia, Idea generation, creativity, and incentives, Marketing Science, 25, 411-425, 2006.

[51] E. von Hippel, Democratizing innovation, MIT Press, Cambridge, Mass., 2005.

[52] E. von Hippel, "Sticky Information" and the locus of problem solving: Implications for innovation, Management Science, 40, 4, 1994, pp. 429-439.

[53] E. von Hippel, and G. von Krogh, Open source software and the "private-collective" innovation model: issues for organization science, Organization Science, 14, 2, 2003, pp. 209-223.

[54] P.-D. Walcher, Der Ideenwettbewerb als Methode der aktiven Kundenintegration, Gabler, Wiesbaden, 2007.

[55] B. Wheaton, B. Muthén, D.F. Alwin, and G.F. Summers, Assessing reliability and stability in panel models, In: Heise, D.R., (ed.), Sociological Methodology, Jossey-Bass, San Francisco, 1977, pp.

[56] A. White, and B.L. Smith, Assessing advertising creativity using the creative product semantic scale, Journal of Advertising Research, 41, 6, 2001, pp. 27-34.

\section{Appendix}

N1: The idea is novel.

N2: $\quad$ The idea is unique or at least rare.

N3: The idea is imaginative, uncommon or surprising.

N4: The idea is revolutionary.

N5: The idea is radical.

N6: The idea is trendy.

R1: The idea has a clearly described customer benefit.

R2: The idea enables the initiator to realize an attractive market potential.

R3: The idea enables the initiator to build up strategic competitive advantages.

F1: $\quad$ The idea is technically feasible.

F2: The idea is economically feasible.

F3: The idea fits the initiator's image.

C1: The idea is precise, complete and exactly described.

C2: The idea is mature.

C3: The idea's utility is clearly described. 